\title{
Histological effects of pre-exposure prophylactic consumption of sulfa drugs on Liver and Kidney of albino Wister rats (Rattus novergicus).
}

\author{
Odigie, B.E. ${ }^{1}$ \\ ${ }^{I}$ Department of Medical Laboratory Sciences, School of Basic Medical Sciences, College of Medical sciences, \\ University of Benin, P.M.B. 1154, Benin City, Edo State.
}

\begin{abstract}
Health concerns over pre-exposure prophylactic abuse of drugs have been reported. However, histological perspectives are not very common. This work is designed to investigate the morphological alteration of visceral organs (kidney and liver) of albino Wister rats pre-exposed to prophylactic consumption of sulfonamide based drugs. 30 albino rats of both sexes, with average weight of $198.50 \mathrm{~g}$ were randomly selected into 4 treatment cages $(A, B, C \& D)$ and a Control cage $(E)$ making a total of 6 rats per cage. Graded dose of Larido $^{(s p)}$ were orally administered to the rats. Cages A-D received 1.0, 2.0, 3.0, $4.0 \mathrm{mg} / \mathrm{kg}$ body weight respectively. Cage E serves as the control group and received no drug treatment. Commercially purchased drinking water, standard top feed ${ }^{(R)}$ was given ad libitum, for 21 days. The animals were weighed before and after commencement of drug administration. Dullness and restlessness were observed and was carefully noted on all treated animals, but were marked in high dose treated animals in (Cages $C$ and D). On day 22, the animals were sacrificed by cervical dislocation; gross examination was done and was quickly fixed in 10\% buffered neutral formalin for routine histological study. Cut tissue at 3-5mm was processed according to paraffin embedding technique while section was cut at 3-5microns using haematoxylin and eosin method for light microscopy. Grossly, the organs of the high dose treatment animals in Cage C and D showed no apparent changes while histological findings after $H \& E$ method indicated that the treatment sections showed inflammatory cells, congested glomerulus, haematoma, thickening of the interstitial cells and vacuolation with congestive and tubular necrosis as compared to the control group. Decrease in body weights of the rats at the end of the study were statistically significant $(p<0.05)$ in the treatment groups $B, C$ and D. Hence, this study shows that pre-exposure prophylactic consumption of sulfonamide based drugs used at a higher doses may have such cellular defects /adverse effects on the visceral organs of human in a similar circumstances.
\end{abstract}

Keywords: Histological technique, Laridox ${ }^{(S P)}$, Prophylaxis, Pyrimethamine and Sulfadoxine.

\section{Introduction}

Malaria is a public health problem in over 100 countries worldwide, inhabited by over 2 billion people. It occurs in tropical and subtropical regions, including parts of the Americas, Asia and Africa. About $85 \%$ of the 300 to 500 million cases annually occur in Africa, over 50\% of them in five countries: Nigeria, Democratic Republic of the Congo, Ethiopia, Tanzania and Kenya. ${ }^{[1]}$

Nigeria is malaria endemic; therefore, chemoprophylaxis remains the primary method for malaria prevention since no vaccine is available currently. ${ }^{[2]}$ It can be prevented by the use of prophylactic, or preventative, drugs; by mosquito eradication through indoor spraying with insecticides; or by avoiding mosquito bites by using mosquito nets impregnated with insecticide ${ }^{[1]}$

Current practice in treating cases of malaria is based on the concept of combination therapy, since this offers several advantages, including reduced risk of treatment failure, reduced risk of developing resistance, enhanced convenience, and reduced side-effects. Prompt parasitological confirmation by microscopy, or alternatively by rapid diagnostic tests, is recommended in all patients suspected of malaria before treatment is started ${ }^{[3]}$ Treatment solely on the basis of clinical suspicion should only be considered when a parasitological diagnosis is not accessible. ${ }^{[3]}$

A lot of drugs have been used over the years to combat the scourge of malaria, such drugs include those of quinine derivaties, local mixtures like leaves of indica, Chinese root extract e.t.c. Likewise, prophylaxis have also been used for therapy such as pyrimethamine derivatives. Most sulfonamide derivatives have been used such as Laridox, ${ }^{(\mathrm{SP})}$ Maldox, fansidar ${ }^{\circledR}$, Amalar ${ }^{\circledR}$, etc. while Laridox ${ }^{(\mathrm{SP})}$, been an alternative approach to chloroquine resistant falciparum, has been increasingly used for prophylaxis.

The activity of sulfonamides is very sensitive to environment, and this limitation affects the activity of sulfonamides in particular fluids and tissues, such as purulent material, as well as the ability of laboratories to standardize minimum inhibitory concentrations (MIC) of sulfonamides necessary in vivo to inhibit specific cultured bacteria ${ }^{[4]}$ Resistance of animal pathogens to sulfonamides is widespread as a result of more than 50 
years of therapeutic use ${ }^{[5] ;{ }^{[4]}}$ and this limits their effectiveness; however, sulfonamides are still widely used in combination with other medications, as in the case of the potentiated sulfonamides.

The use of two antimalarials simultaneously, especially when the antimalarial have different mechanisms of action, has the potential for inhibiting the development of resistance to either of the components. The efficacy of a combination of a 4-aminoquinoline drug (either chloroquine or amodiaquine) with sulfadoxine/pyrimethamine has been reviewed ${ }^{[6]}$

${ }^{[2]}$ Examined the Influence of chloroquine and sulfadoxine on biochemical and hematological indices in albino rats; he concluded that single therapy of the tested drugs (CS and CP) particularly CS (nivaquine) was more toxic than their combination therapy $(\mathrm{CS}+\mathrm{SP}$ and $\mathrm{CP}+\mathrm{SP})$ within the short period of administration. $\mathrm{He}$ further stated that the acute toxicity observed on biochemical and hematological indices of the rats were associated with clinical features of blood as well as hepatocellular and renal necrosis.

${ }^{[7]}$ Showed that tenoxicam, which is a member of oxicams family produce stabilization of lysosomal membrane which may be attributed to the anti-inflammatory effect of the drug, probably. According to him the findings indicates that LOR may exert the same effects as tenoxicam on liver and kidney lysosomal membranes while ${ }^{[8]}$ observed similar alterations but in lysosomal enzymes which they claim may contribute to explain the hepatotoxicity and nephrotoxicity under the effects of some NSAIDS drugs (in which Sulfonamide is an active ingredient) and inturn it leads to the labialization of the lysosomal membrane and further leads to the leakage of lysosomal enzymes ${ }^{[9] ;[10]}$.

Moreso, ${ }^{[11] ;[12]}$ worked on antimalarial drugs containing fixed combination of Pyrimethamine and Sulfadoxine but was centered on haematological parameters. According to them, the drugs administered caused elevation in hematological indices resulting in hemoglobinuria, polycythemia, leukocytosis, neutrophilia and lymphocytosis. Hypoxia leading to polycythemia (increased PCV level), acute stress increases number of WBC, high white blood cell counts which may be due to inflammation and immune response was observed by ${ }^{[13]}$.

Hence, keeping in view the adverse drug reactions associated with the common anti-malaria drugs (sulfadoxine, quinine and schizontocidal drugs called chloroquine) used in Nigeria, earlier research conducted by ${ }^{[11]}$ revealed abuse of these drugs by consumers on self-medication in Nigeria being malaria endemic country. In view of this, the present work is therefore design to study the influence of the fixed combination of sulfadoxine and pyrimethamine on histological morphology in albino rats (Rattus novergicus).

\subsection{Materials and Methods}

Standard histological methods and materials were used as described by ${ }^{[14]}$

\subsection{Animal care ethics}

The School of Basic Medical Sciences, College of medical sciences, University of Benin, Benin City, gave approval for the work to commence. The rats were obtained and maintained in the Animal House of the Department of Medical Biochemistry, School of Basic Medical Sciences, University of Benin, Benin City, Edo state, Nigeria. These rats were kept and acclimatized in the Animal House of the Department of Medical Laboratory Sciences, School of Basic Medical Sciences, University of Benin, Benin City for two weeks. Enough food (Standard top feed ${ }^{\circledR}$ and commercially purchased UNIBEN table water with NAFDAC Reg. no 014597 was provided.

\subsection{Animal Grouping}

The animal studies were carried out in compliance with policies outlined in the 'Guide for the Care and Use of Laboratory Animals', published by the US National Institute of Health (NIH Publication No. 85-23, revised 1996). For this study, 30 Albino wistar rats were divided into five (5) groups of 6 rats per cage and was labeled as cages $\mathrm{A}, \mathrm{B}, \mathrm{C}, \mathrm{D}$ and $\mathrm{E}$.

\subsection{Determination of body weight}

The method described by ${ }^{[16]}$ was used to determine body weight of experimental rats. Individual rat was monitored for daily gain in body weight using digital electronic balance (Gilbertini, Italy). Gain in weight was obtained from the relationship given below: Daily gain in weight= Final day Weight - Initial day Weight, where the average mean weight was $198.50 \mathrm{~g}$.

\subsection{Design and Conduct of experiment}

Cages A, B, C and D were treated with a graded doses of Laridox ${ }^{(\mathrm{SP})}$ tablet in the order of 1.0, 2.0, 3.0, 4.0 $\mathrm{mg} / \mathrm{kg}$ body weight respectively with regards to the L. $\mathrm{D}_{50}$ of $22 \mathrm{mg}$ of the drug, while Cage E served as the control group without experimental dose. 


\subsection{Drug Administration}

In Nigeria, a genuine Laridox ${ }^{(\mathrm{SP})}$ drug has been documented to possess the actual amount of active ingredients (Sulfonamide) in a fixed combination of 500mg Sulfadoxine $+25 \mathrm{mg}$ Pyrimethamine on analysis. The graded dose was diluted to appropriate concentrations using commercially purchased UNIBEN table water with NAFDAC no 01-4597. The drugs Laridox ${ }^{(\mathrm{SP})}$ when reconstituted was administered orally using standard $5 \mathrm{ml}$ syringes for 21 days at the interval of 2 (two) days. It was purchased from government approved pharmacy opposite University of Benin Teaching Hospital, Benin City, Edo state with NAFDAC registration number 043353. Manufacturer: Ipca Laboratories Ltd. Sejavta, ratlam 457 002, Regd. Off.; 48, Kandivii Ind. Estate, Mumbai 400067 India.

\subsection{Location and Duration of Study}

This study was conducted in the department of Medical Laboratory Science, Histopathology subdepartmental Laboratory, School of Basic Medical Sciences, College of Medical Sciences, University of Benin, Benin City, Edo State, Nigeria, west africa. Animal acclimatization, drug administration, Grossing, Tissue processing, Microtomy, Staining and microscopic examination of histological sections lasted for two months (January $4^{\text {th }}$ to March $4^{\text {th }} 2013$ ).

\subsection{Statistical Analysis}

Data are presented as Means \pm SD and analyzed using ANOVA and Duncan post hoc test and significance was determined at $\mathrm{p}<0.05$.

\subsection{Methodology}

Table 1: Oral consumption of Sulfadoxine + Pyrimethamine $\left(\right.$ Laridox $\left.{ }^{(\mathrm{SP})}\right)$ by 30 albino rats

\begin{tabular}{|l|l|l|l|l|}
\hline Cages & $\begin{array}{l}\text { Number of } \\
\text { rats }\end{array}$ & Average Weight & Dosage mg/kg Body Weight & Administration \\
\hline A & 6 & 193.32 & 1.0 & 21 Days \\
\hline B & 6 & 198.28 & 2.0 & 21 Days \\
\hline C & 6 & 200.14 & 3.0 & 21Days \\
\hline D & 6 & 200.52 & 4.0 & 21 Days \\
\hline E & 6 & 200.25 & 0.0 & 21 Days \\
\hline
\end{tabular}

Average weight of rats $=198.50 \mathrm{~g}$

Maximum volume of water $=6 \mathrm{ml}$

Oral consumption of clinical dose of Laridox ${ }^{(\mathrm{SP})}$ was prepared and given to the animals. The drug was grounded, dissolved in water and diluted to approximate concentration using commercially purchased UNIBEN table water.

Each of the animals in cages A, B, C and D were picked one at a time with a hand towel and appropriate volumes in $\mathrm{ml}$ of the drugs were administered to the animals orally, using a sterile $5 \mathrm{ml}$ syringes. All animals were sacrificed at the end of the experiment. The visceral organs of interest (kidney and liver) were observed grossly and thereafter processed for histological examination. Sections of the tissues were obtained using the hertz rotary microtome (Cambridge mode). Staining of the sections was according to haematoxylin and eosin staining technique as described by ${ }^{[14]}$.

\section{Results}

Table 2. Results of sulfa drugs Toxicity analysis of Albino wistar rats On pre-exposure prophylactic consumption of Laridox ${ }^{(\mathrm{SP})}$ for 21 days at 1 day interval.

\begin{tabular}{|l|l|l|l|l|l|}
\hline Cage & $\begin{array}{l}\text { Dose } \\
\mathrm{mg} / \mathrm{kg}\end{array}$ & $\begin{array}{l}\text { Average weight } \\
\text { before administration }\end{array}$ & $\begin{array}{l}\text { Average weight after } \\
\text { administration }\end{array}$ & $\begin{array}{l}\text { Physical weight loss / } \\
\text { or gain }\end{array}$ & $\begin{array}{l}\text { Activities } \\
\text { /dullness }\end{array}$ \\
\hline $\mathrm{A}$ & 1.0 & $193.32 \pm 1.8$ & $193.10 \pm 1.3$ & $\downarrow$ & \pm \\
\hline $\mathrm{B}$ & 2.0 & $198.28 \pm 2.3$ & $197.56 \pm 1.7$ & $\downarrow$ & \pm \\
\hline $\mathrm{C}$ & 3.0 & $200.14 \pm 1.8$ & $197.23 \pm 1.4$ & $\ddagger$ & ++ \\
\hline $\mathrm{D}$ & 4.0 & $200.52 \pm 1.2$ & $196.47 \pm 1.8$ & $\ddagger$ & ++ \\
\hline E & 0.0 & $200.25 \pm 1.4$ & $202.56 \pm 1.8$ & $\uparrow$ & - \\
\hline
\end{tabular}


Table 3: Histological scoring

\begin{tabular}{|l|l|l|l|l|l|l|l|}
\hline Cage & $\begin{array}{l}\text { Dose } \\
\text { in } \\
\mathrm{mg} / \mathrm{kg}\end{array}$ & $\begin{array}{l}\text { Increase in } \\
\text { urinary } \\
\text { pole. }\end{array}$ & $\begin{array}{l}\text { Inflammatory } \\
\text { cell } \\
\text { infiltration }\end{array}$ & $\begin{array}{l}\text { Distortion } \\
\text { of central } \\
\text { vein }\end{array}$ & $\begin{array}{l}\text { Inflammatory } \\
\text { cell / distortion } \\
\text { of bile duct }\end{array}$ & $\begin{array}{l}\text { Hepato- } \\
\text { cellular } \\
\text { necrosis }\end{array}$ & vacoulation \\
\hline $\mathrm{A}$ & 1.0 & - & + & + & + & - & - \\
\hline $\mathrm{B}$ & 2.0 & - & + & + & + & \pm & \pm \\
\hline $\mathrm{C}$ & 3.0 & ++ & ++ & ++ & ++ & + & + \\
\hline $\mathrm{D}$ & 4.0 & ++ & ++ & ++ & ++ & ++ & ++ \\
\hline $\mathrm{E}$ & 0.0 & - & - & - & - & - & - \\
\hline
\end{tabular}

$\begin{array}{lll}\text { Key } & & \\ \uparrow & \rightarrow & \text { Slight increase in weight } \\ f & \rightarrow & \text { Marked increase in weight } \\ \downarrow & \rightarrow & \text { Slight weight loss } \\ \pm & \rightarrow & \text { Severe weight loss } \\ + & \rightarrow & \text { Presence of features } \\ \pm & \rightarrow & \text { Intermediate features } \\ ++ & \rightarrow & \text { Marked presence of features } \\ - & \rightarrow & \text { Absence of features }\end{array}$

Dullness and restlessness was observed amongst all treated animals, but was marked in high dose treated animals in (Cages C and D). Necrosis was more pronounced and prominent in the high dose treated animals. The low dose treated animals showed little or no weight loss as compared to the severe weight loss observed in the high dose treated animals.

Upon grossing, the organs of the high dose treatment animals showed variation in colouration while histologically; sections reveals more features of toxic reactions in the organs of the treatment animals as compared to the control groups and were more pronounced in the liver. Also, liver section shows evidence of inflammatory cell infiltration, bile ducts distortion, marked presence of hematoma in the central canal with slight hepatocellular necrosis and vacuolation being prominent in the high dose treatment liver section (Refer to Fig 4 \& 8). There were marked increases in the urinary pore of the renal corpuscle, inflammatory cell infiltration was observed at the perivascular area showing vast evidence of congestive or congested glomerulus (Fig $3 \& 5$ ).

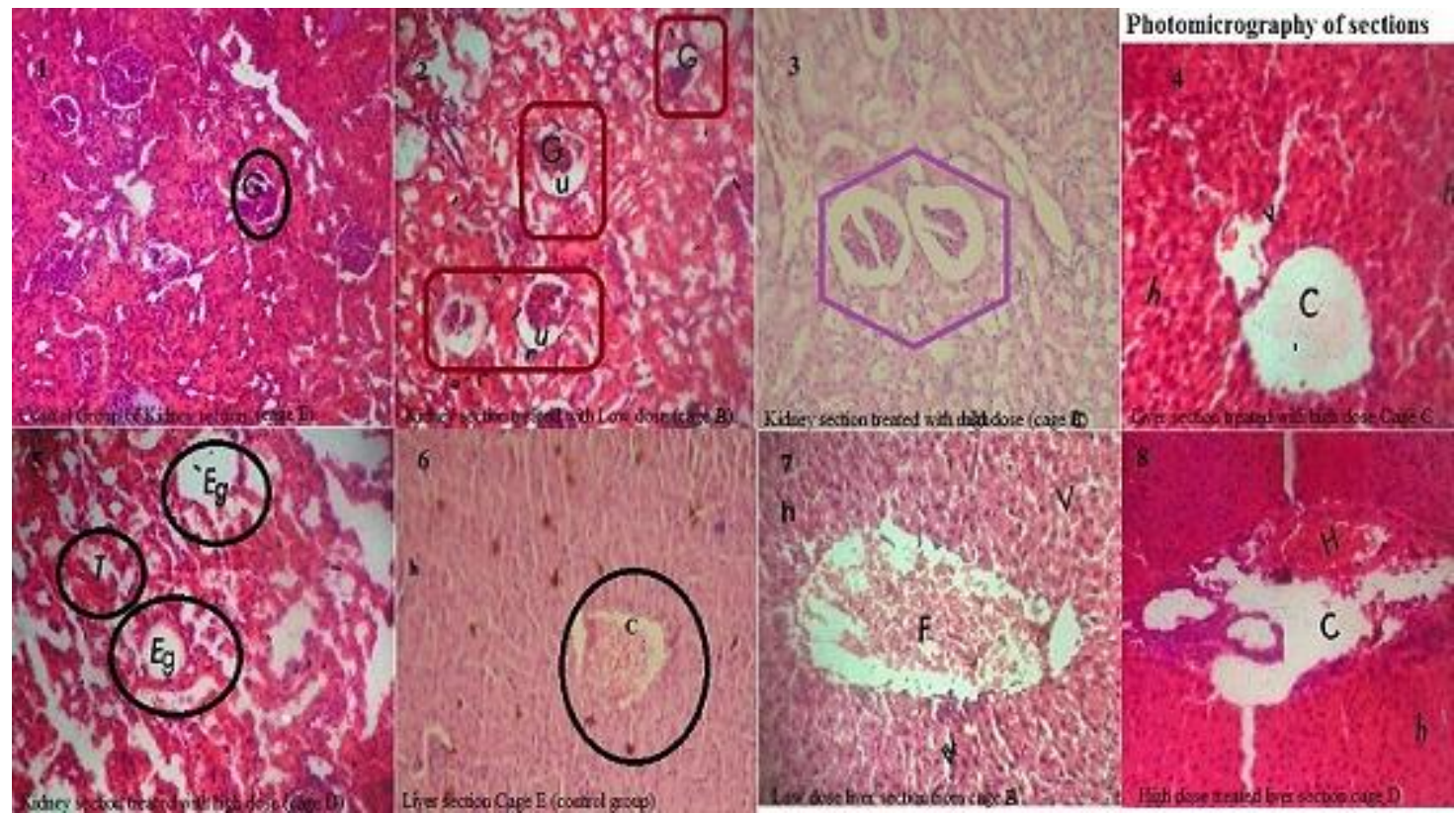

Fig 1- Shows Kidney section of a normal histology. (Control group in cage E)

Fig 2- Shows kidney section of rats treated with low dose. (Cage B)

Fig 3- kidney section of rats treated with high dose. (Cage C): shows marked increase in the urinary pore of the renal corpuscle and congestive or congested glomerulus 
Fig 4- Liver section of rats treated with high dose. (Cage C): Shows slight hepatocellular necrosis and vacuolation.

Fig 5- kidney section of rats treated with high dose. (Cage D): shows inflammatory cell infiltration observed at the perivascular area with evidence of erosion of the glomerulus in large doses.

Fig 6- Control group in cage E: Shows histology of normal Liver section, with frank red blood cells within the central vein.

Fig 7- Liver section treated with low dose (Cage B): shows presence of frank red blood cell within the central vein.

Fig 8- Liver section treated with high dose (Cage D). Shows evidence of inflammatory cell infiltration, bile ducts distortion and marked presence of hematoma in the central canal.

Note: Section from Cage A. (Kidney and Liver) shows little or no remarkable features of toxicity, hence the slides were omitted.

List of Abbreviation: $\mathrm{CP}=$ Chloroquine + Pyrimethamine, $\mathrm{SP}=$ Sulfadoxine + Pyrimethamine,

$\mathrm{CS}=$ Chloroquine + Sulfadoxine, $\mathrm{H} \& \mathrm{E}=$ Heamatoxylin and Eosin, NSAIDS $=$ non-

steroidal anti-inflammatory drugs, $\mathrm{PCV}=$ Packed cell volume, LOR= Line of

Response

\subsection{Discussion}

From the result obtained in this work, greater histological effects; as evident by cellular changes was observed in the liver. These observations agrees with those of ${ }^{[16]}$ in which animal model indicated such liver toxicity and he concluded that the effect is dose related and reproduceable.

Meanwhile, Deleterious effects observed in the high dose kidney section may partially be in agreement with ${ }^{[17]}$ who noted sulfadoxine induced increase in serum creatinine level; and thus states that "it may not represent a real deterioration in renal function", though their conclusion was drawn from the biochemical point of view.

There were also signs of an increase in the urinary pole of the renal corpuscle of the kidney, where the Kidney showed marked inflammatory cells infiltration. The weight gain reported by ${ }^{[18]}$ was observed in animals in the control groups. The low dose treatment animals show a negligible weight loss while the high dose treatment animals showed an appreciable loss in weight.

[11]; [12] did a similar work on antimalarial drugs containing fixed combination of Pyrimethamine and Sulfadoxine but he checked on haematological parameters. While the drugs administered caused elevation in hematological indices resulting in hemoglobinuria, polycythemia, leukocytosis, neutrophilia and lymphocytosis, which further confirms the result from the present study on visceral organs of the same albino rats used as models. Hypoxia leads to polycythemia (increased PCV level), acute stress increases number of WBC. High white blood cell counts may be due to inflammation and immune response ${ }^{[13]}$; this is also in line with the inflammatory cells observed during microscopy of the Liver sections studied.

More so, the presence of monocytes in CS, CP and CS+SP and eosinophil and basophil in CS administered groups indicate chronic inflammation and allergic response respectively in administered rats. However, hemoglobinuria and polycythemia have been associated with chronic chemical exposure such as sulfonamides, other substances producing methaemoglobin and sulphaemoglobin. Crenated blood cells observed in CS and CP administered groups showed destructive property of the drugs on red blood cells. According to ${ }^{\text {[12] }}$ Crenation is the contraction of a cell after exposure to a hypertonic solution due to the loss of water through osmosis. The effects of crenation is visible in red blood cells, or erythrocytes, as they become distorted in shape rather than maintaining the usual disc-like shape with dimple that the blood cell normally has instead.

According to ${ }^{[2]}$ while examining the Influence of chloroquine and sulfadoxine on biochemical and hematological indices in albino rats; concluded that Single therapy of the tested drugs (CS and CP) particularly $\mathrm{CS}$ (nivaquine) was more toxic than their combination therapy (CS+SP and CP+SP) within the short period of administration. The acute toxicity observed on biochemical and hematological indices was associated with clinical features of blood, hepatocellular and renal necrosis, which also confirms our findings using histological indices as compared to biochemical and haematological indices used earlier.

[7] showed that tenoxicam, which is a member of oxicams family produce stabilization of lysosomal membrane which may be attributed to the anti-inflammatory effect of the drug, probably. These findings indicate that LOR may exert the same effects as tenoxicam on liver and kidney lysosomal membranes. In the present results, which shows morphological alterations in the anatomical architecture of both organs under investigation is in close relation with ${ }^{[8]}$ who observed similar alterations but in lysosomal enzymes which they claim may contribute to explain the hepatotoxicity and nephrotoxicity under the effects of some NSAIDS drugs (in which Sulfonamide is an active ingredient) which leads to labialization of the lysosomal membrane and in turn leads to the leakage of lysosomal enzymes ${ }^{[19] ;[10] \text {. }}$ 
4.2 Conclusion and Recommendation: The results obtained in this study revealed that pre-exposure prophylactic consumption of sulfonamide drugs used at a high dose adversely affect the liver and Kidney morphology of white rats. Hence, the following recommendation has been put together as follows:

1. That further studies be carried out to corroborate these findings.

2. That strict compliance to Doctor's prescription should be enforced.

3. That self-medication should be discouraged.

4. The need for Nigerian governments to formulate laws and appropriate penalty against petty trading of drugs should be put in place.

5. Thus the need to restrict access to drugs to hospital and pharmaceutical stores.

6. The need to sensitize the public on the danger in drug abuse.

7. Overzealous prescription of drugs by health practitioners without laboratory follow-ups should be discouraged with strict punishment by the Medical council /government.

\section{References}

[1]. World Health organization; World Malaria Report, http://www.who.int/malaria/publications/atoz/9789241563697/en/index.html 2008.

[2]. SOO Ajiboso, Influence of chloroquine and sulfadoxine on biochemical and hematological indices in albino rats, Indian Journal of Drugs and Diseases, 1(5) 2012, 117

[3]. World Health Organization. Guidelines for the treatment of malaria 2nd ed. 2010, 194. ISBN 978-92-4-154792-5

[4]. J. Riviere, A.L. Craigmill, S.F. Sundlof, Handbook of comparative pharmacokinetics and residues of veterinary antimicrobials. Boca Raton, FL: CRC Press, Inc., 1991, 339-407.

[5]. J.F. Prescott and J.D. Baggott, editors. Antimicrobial therapy in veterinary medicine, 2nd ed. Ames, IA: Iowa State University Press, 1993,119-26.

[6]. H.M. McIntosh and B.M. Greenwood, Chloroquine or amodiaquine combined with sulfadoxine-pyrimethamine as a treatment for uncomplicated malaria - a systematic review. Annals of Tropical Medicine \& Parasitology, 93, 1998, 265-270.

[7]. K.P. Poonguzhali, C. Hariprasad, A.N. Chandrasekaran, C. Gowri and N. Ganesan, Effect of Cynodon dactylon and tenoxicam on the lysosomal enzyme activities in the cartilage tissue of osteoarthritic guinea pigs. Journal of Clinical Biochem Nutr 24(3), 1998, $141-146$.

[8]. S.E. Omaima, A. Samy, A. El-Azim, M.E. Kamal and M.B. Maged, Is Lysosomal Enzymes Changes Important In the Pathogenesis of Liver And Kidney Injury Induced By Short and Long Term Administration of Some NSAID' Drugs in Rats? Life Science Journal, 9(4), 2012

[9]. J.D Bancroft and G. Marilyn, Theory and practice of histological techniques. 5th London Edinburgh New York Philadelphia St. Louis Sydney, Toronto, 2002

[10]. MA Khandkar, D.V. Parmar, M. Das and S.S. Katyare, Is activation of lysosomal enzymes responsible for paracetamol-induced hepatotoxicity and nephrotoxicity? J. Pharm. Pharmacol 48, 1996, 437-440.

[11]. SOO Ajiboso, Determination of sex differences in antimalaria therapy on hematological indices of albino rats. Nigerian J. Gender and Develop. 6(1), 2006, 1-7.

[12]. R Sood, Medical laboratory technology methods and interpretations, Jaypee (New Delhi $5^{\text {th }}$ edn., 1999, $175-215$.

[13]. G.C. Bagby, Leucopenia and leukocytosis. In: Goldman L, Austelo, D educ. Cecil Med. 23rd ed. (Philadelphia, Pa: Saunders Elsevier, 2007) 173.

[14]. J.D Bancroft and G. Marilyn, Theory and practice of histological techniques. (5th London Edinburgh New York Philadelphia St. Louis Sydney. Toronto 2002).

[15]. SOO Ajiboso, M. Gbate, O.I. Adejumo and S.O. Adeyemo, A study on the performance of grain residues rations in ANAK 2000 chicks. Scientific Research and Essay. 2 (8), 2007, 353-357.

[16]. J.P.Buchweit, P.E. Ganney, S.J. Bursian and R.A. Roth, Underlying endothoxemia Augumented Toxic responses to sulphonamides. Is there a relationship to drug idiosyncrasy? Michigan state University 18, 2002, 220-234.

[17]. C Hottelart, N. El Esper, J.M. Achard, A. Pruna and A. Fournier, Fenofibrate increases blood creatine but does not change the glomerular filtration rate in patients with mild renal insufficiency, Nephrol. 20, 1999, 41-44

[18]. B. Thornley, C.E. Adams and G. Awad, chlorpromazine versus placebo for schizophrenia Cochran library review, Oxford 18, 2002, 183-187.

[19]. M Bhadauria and S.N. Kumar, Reversal of acetaminophen induced subchronic hepatorenal injury by propolis extract in rats. Environ Toxicol Pharmacol 27, 2009, 17-25 